\title{
COMMENTARY
}

\section{On the imperfect synchrony between patient and ventilator}

\author{
Paolo Navalesi*1,2 \\ See related research by Gutierrez et al., http://ccforum.com/content/15/4/R167
}

\begin{abstract}
Because patient-ventilator asynchrony (PVA) is recognized as a major clinical problem for patients undergoing ventilatory assistance, automatic methods of PVA detection have been proposed in recent years. A novel approach is airflow spectral analysis, which, when related to visual inspection of airway pressure and flow waveforms, has been shown to reach a sensitivity and specificity of greater than $80 \%$ in detecting an asynchrony index of greater than $10 \%$. The availability of automatic non-invasive methods of PVA detection at the bedside would likely be of benefit in intensive care unit practice, but they may be limited by shortcomings, so clear proof of their effectiveness is needed.
\end{abstract}

Non-invasive automatic methods to detect patient-ventilator asynchrony (PVA) have been proposed repeatedly in recent years [1-5]. The reason for this increasing interest is the notion that, unlike patients with an asynchrony index (AI) of less than $10 \%$, those with high rates of PVA (as defined by an AI of greater than 10\%) are characterized by poorer outcome (that is, longer durations of mechanical ventilation [6-8] and ICU stay $[7,8]$, a reduced number of ventilator-free days [8], a higher rate of tracheotomy [7], and lower probabilities of survival [6] and home discharge [8]).

We do not know whether PVA itself causes this increased morbidity by prolonging the time spent on mechanical ventilation or instead is a marker of poor respiratory function in sicker patients at increased risk of high morbidity. In the first case, decreasing PVA would improve a patient's outcome, whereas in the second case, PVA would just represent a prognostic

\footnotetext{
*Correspondence: paolo.navalesi@med.unipmn.it

'Department of Clinical and Experimental Medicine, Università del Piemonte

Orientale 'Amedeo Avogadro', Via Solaroli 17, 28100 Novara, Italy

Full list of author information is available at the end of the article
}

factor. Nevertheless, in both cases, recognizing PVA would be a valuable clinical piece of information.

In this issue of Critical Care, Gutierrez and colleagues [1] present a new method that is based on airflow spectral analysis for the detection of PVA and that is characterized not by synchronous breaths but by a less organized spectral pattern. When this novel approach is correlated to visual inspection of airway pressure and flow waveforms in detecting an AI of greater than 10\%, sensitivity and specificity both exceeded $80 \%$, and this led the authors to conclude that this method could be adapted to ventilators for PVA monitoring. Such a continuous non-invasive monitoring device would facilitate the recognition of PVA and help to evaluate the effectiveness of measures adopted to face it, such as reducing sedation, changing ventilator mode, or varying ventilator settings, chiefly by decreasing the amount of assistance or by improving the match between neural and mechanical inspiration or by both means.

The studies in which PVA is assessed by visual inspection of the ventilator waveforms are commonly performed by trained observers or researchers who have a high level of knowledge in this specific field and who might not reflect the average skill of the ICU professionals. New data on the ability of ICU physicians to recognize PVA at the bedside show that the chance to detect PVA by ventilator waveform observation in the 'real world' is less than anticipated [9], making automatic methods of PVA detection, such as the one proposed by Gutierrez and colleagues [1], even more helpful than expected. However, it is worthwhile to consider the potential limitations of (a) the automatic methods of PVA detection in general and (b) this approach acting in the frequency domain in particular.

It is unclear whether inspection of airway pressure and flow waveform represents a valid gold standard. Some studies proposing automatic methods of PVA detection use indices of inspiratory effort, such as esophageal $[2,5]$ and trans-diaphragmatic [4] pressure. The latter approach is not susceptible to potential biases arising from neuroventilatory uncoupling in those situations in which, although the excitation of the respiratory muscles (neural 
effort or drive) generates pressure (mechanical effort), this pressure is not translated into flow and volume [911]. Indeed, in extreme cases of poor neuro-mechanical coupling (that is, impaired transformation of the muscle electrical activation into pressure), even the esophageal and trans-diaphragmatic pressures might not be completely effective in ascertaining a patient's neural drive $[9,11,12]$. Our chances of determining the occurrence of neuro-ventilatory and neuro-mechanical uncoupling by visual inspection of the airway pressure and flow waveforms are limited, but it is uncertain to what extent this may actually hamper our ability to detect PVA at the bedside.

More specifically, to consider a method based on an analysis of the frequency spectrum [1], further evaluation is necessary to clarify whether such an approach may fit (a) modes of ventilation that allow the patient to retain full control of the breathing pattern and that are characterized by high breath-by-breath variability [12] and (b) non-invasive ventilation in which asynchronies frequently occur $[13,14]$ and, given that the patient is usually alert, non-chemical behavioral inputs influence the neural drive and breathing pattern [15].

In the last decade, we have greatly increased our knowledge about PVA. We are now aware that it occurs more frequently than previously perceived and, given its correlation with poorer outcome, is clinically relevant. Further research is necessary to address several unresolved issues, and recognition of PVA in the clinical setting is surely one of these. The imperfect synchrony between patient and ventilator has become a stand-alone topic within the field of mechanical ventilation.

\section{Abbreviations}

$\mathrm{Al}$, asynchrony index; ICU, intensive care unit; PVA, patient-ventilator asynchrony.

\section{Competing interests}

The author declares that he has no competing interests.

\section{Author details}

${ }^{1}$ Department of Clinical and Experimental Medicine, Università del Piemonte Orientale 'Amedeo Avogadro', Via Solaroli 17, 28100 Novara, Italy. ${ }^{2}$ Anesthesia and Intensive Care Medicine, Sant'Andrea Hospital, Corso M. Abbiate 21, 13100 Vercelli, Italy.
Published: 18 August 2011

References

1. Gutierrez G, Ballarino GJ, Turkan H, Abril J, De La Cruz L, Edsall C, George B, Gutierrez S, Jha V, Ahari J: Automatic detection of patient-ventilator asynchrony by spectral analysis of airway flow. Crit Care 2011, 15:R167.

2. Cuvelier A, Achour L, Rabarimanantsoa H, Letellier C, Muir JF, Fauroux B: A noninvasive method to identify ineffective triggering in patients with noninvasive pressure support ventilation. Respiration 2010, 80:198-206.

3. Chen CW, Lin WC, Hsu CH, Cheng KS, Lo CS: Detecting ineffective triggering in the expiratory phase in mechanically ventilated patients based on airway flow and pressure deflection: feasibility of using a computer algorithm. Crit Care Med 2008, 36:455-461.

4. Mulqueeny Q, Ceriana P, Carlucci A, Fanfulla F, Delmastro M, Nava S: Automatic detection of ineffective triggering and double triggering during mechanical ventilation. Intensive Care Med 2007, 33:2014-2018.

5. Younes M, Brochard L, Grasso S, Kun J, Mancebo J, Ranieri M, Richard JC, Younes $\mathrm{H}$ : A method for monitoring and improving patient: ventilator interaction. Intensive Care Med 2007, 33:1337-1346.

6. Chao DC, Scheinhorn DJ, Stearn-Hassenpflug M: Patient-ventilator trigger asynchrony in prolonged mechanical ventilation. Chest 1997, 112:1592-1599.

7. Thille AW, Rodriguez P, Cabello B, Lellouche F, Brochard L: Patient-ventilator asynchrony during assisted mechanical ventilation. Intensive Care Med 2006, 32:1515-1522.

8. de Wit M, Miller KB, Green DA, Ostman HE, Gennings C, Epstein SK: Ineffective triggering predicts increased duration of mechanical ventilation. Crit Care Med 2009, 37:2740-2745

9. Colombo D, Cammarota G, Alemani M, Carenzo L, Barra F, Vaschetto R, Slutsky AS, Della Corte F, Navalesi P: Efficacy of ventilator waveforms observation in detecting patient-ventilator asynchrony. Crit Care Med 2011 Jun 23. [Epub ahead of print]

10. Younes M: Proportional assist ventilation, a new approach to ventilatory support. Theory. Am Rev Respir Dis 1992, 145:114-120.

11. Sinderby C, Navalesi P, Beck J, Skrobik Y, Comtois N, Friberg S, Gottfried SB, Lindstrom L: Neural control of mechanical ventilation in respiratory failure. Nat Med 1999, 5:1433-1436.

12. Navalesi P, Costa R: New modes of mechanical ventilation: proportional assist ventilation, neurally adjusted ventilatory assist, and fractal ventilation. Curr Opin Crit Care 2003, 9:51-58.

13. Vignaux L, Vargas F, Roeseler J, Tassaux D, Thille AW, Kossowsky MP, Brochard $L$, Jolliet $P$ : Patient-ventilator asynchrony during non-invasive ventilation for acute respiratory failure: a multicenter study. Intensive Care Med 2009, 35:840-846.

14. Navalesi P, Costa R, Ceriana P, Carlucci A, Prinianakis G, Antonelli M, Conti G, Nava S: Non-invasive ventilation in chronic obstructive pulmonary disease patients: helmet versus facial mask. Intensive Care Med 2007, 33:74-81.

15. Fink BR: The stimulant effect of wakefulness on respiration: clinical aspects. Br J Anaesth 1961, 33:97-101.

doi:10.1186/cc10300

Cite this article as: Navalesi P: On the imperfect synchrony between patient and ventilator. Critical Care 2011, 15:181 